\title{
Anti-atherosclerotic effects of sitagliptin in patients with type 2 diabetes mellitus
}

This article was published in the following Dove Press journal:

Diabetes, Metabolic Syndrome and Obesity: Targets and Therapy

27 July 2015

Number of times this article has been viewed

\section{Seitaro Omoto' \\ Takehito Taniura ${ }^{2}$ \\ Tohru Nishizawa ${ }^{3}$ \\ Takeshi Tamaki ${ }^{3}$ \\ Akira Shouzu ${ }^{4}$ \\ Shosaku Nomura ${ }^{3}$ \\ 'Division of Internal Medicine, Korigaoka Yukeikai Hospital, ${ }^{2}$ Division of Internal Medicine, Daiwa Hospital, ${ }^{3}$ First Department of Internal Medicine, Kansai Medical University, ${ }^{4}$ Division of Internal Medicine, Saiseikai Izuo Hospital, Osaka, Japan}

Correspondence: Shosaku Nomura First Department of Internal Medicine, Kansai Medical University, 2-3-I Shinmachi, Hirakata, Osaka 573-II91, Japan

$\mathrm{Tel}+8 \mathrm{I} 728042754$

Fax +8I 72804204 I

Email nomurash@hirakata.kmu.ac.jp
Background: Advanced glycation end products, selectins, and adiponectin play important roles in the development of atherosclerosis in individuals with diabetes. Sitagliptin has been shown to reduce the concentration of glycated hemoglobin in diabetic patients. However, its effects on soluble receptor for advanced glycation end products (sRAGEs), selectins, and adiponectin in these patients are poorly understood. This study was conducted to assess the effects of sitagliptin on the circulating levels of sRAGEs, monocyte chemoattractant protein-1 (MCP-1), selectins, and adiponectin in patients with type 2 diabetes.

Methods: Diabetic patients eligible for sitagliptin monotherapy or combination therapy (eg, sitagliptin plus a sulfonylurea) were administered sitagliptin $(50 \mathrm{mg} /$ day) for 6 months. Levels of soluble P-selectin (sP-selectin), soluble E-selectin (sE-selectin), soluble vascular cell adhesion molecule-1 (sVCAM-1), MCP-1, sRAGEs, and adiponectin were measured by ELISA at baseline and after 3 and 6 months of treatment.

Results: At baseline, the levels of MCP-1, sP-selectin, sE-selectin, and sVCAM-1 were higher and the level of adiponectin was lower in diabetic patients than in nondiabetic patients. Sitagliptin therapy for 3 and 6 months significantly reduced plasma levels of sP-selectin, sE-selectin, sVCAM-1, and MCP-1 relative to baseline, while significantly increasing adiponectin levels. sRAGEs did not exhibit a statistical significance, although there was an increasing tendency. Furthermore, the reductions in SP-selectin, sE-selectin, sVCAM-1, and MCP-1 during sitagliptin therapy were significantly greater in responders, defined as patients with a significant increase in adiponectin levels, than in nonresponders. In contrast, responders showed a significant increase in the plasma concentration of sRAGEs.

Conclusion: Sitagliptin shows an adiponectin-dependent anti-atherothrombotic effect, which may be beneficial for primary prevention of atherothrombosis, in patients with type 2 diabetes.

Keywords: type 2 diabetes mellitus, sitagliptin, sRAGE, selectins, sVCAM-1, adiponectin

\section{Introduction}

The development of atherosclerosis in patients with type 2 diabetes mellitus (T2DM) may be due to hypercoagulability and platelet hyperaggregability, ${ }^{1,2}$ along with increased levels of platelet activation markers. These changes have been associated with increased risks of cardiovascular events. ${ }^{3,4}$ Diabetes is also characterized by the increased expression of cell adhesion molecules, ${ }^{5}$ which may play a role in the microvascular complications of this disease. The first step in the process of leukocyte migration into the subendothelial space is the adhesion of circulating leukocytes to the endothelium, which may involve adhesion molecules such as P-selectin, E-selectin, and vascular cell adhesion molecule-1 (VCAM-1). These molecules have been associated with vascular 
complications, with higher serum levels of soluble P-selectin (sP-selectin), soluble E-selectin (sE-selectin), and soluble VCAM-1 (sVCAM-1) in patients with diabetes. ${ }^{6,7}$ Patients with postprandial hyperglycemia often have accompanying postprandial hyperinsulinemia. However, the postprandial increase in blood glucose level itself is now considered a risk factor for the progression of atherosclerosis. ${ }^{8}$

Adiponectin, the most abundant adipose tissue-specific protein, is exclusively expressed in and secreted by adipose tissue. ${ }^{9}$ Plasma adiponectin concentrations, which are normally high, have been shown to be reduced in obese individuals $^{9,10}$ and those with T2DM, ${ }^{11}$ and to be closely related to insulin sensitivity. ${ }^{12}$ Adiponectin has been shown to stimulate nitric oxide (NO) production in vascular endothelial cells, ameliorating endothelial function. ${ }^{13,14}$ These observations suggest that the anti-atherogenic properties of adiponectin may involve its NO-dependent antiplatelet effects.

Advanced glycation end products (AGEs), the final products of the nonenzymatic glycation of proteins, ${ }^{15}$ bind to activate receptor for AGEs (RAGEs), enhancing inflammation. ${ }^{16,17}$ RAGEs also promote chronic inflammation, as observed in diabetes and atherosclerosis. ${ }^{18,19}$ In contrast, soluble RAGE (sRAGE), a RAGE isoform lacking the transmembrane domain, is an inhibitor of AGE-RAGE-mediated pathological effects. ${ }^{20}$ For example, sRAGE was shown to protect blood vessels against AGE-RAGE-mediated microvascular damage in patients with T2DM. ${ }^{21}$

Dipeptidyl peptidase- 4 is an enzyme involved in the degradation of the intact (active) incretin hormones, glucagon-like peptide-1 (GLP-1) and glucose-dependent insulinotropic peptide, to their inactive metabolites. GLP-1 and glucosedependent insulinotropic peptide are released by the intestine into the circulation in response to a meal, and both the hormones increase glucose-dependent insulin secretion by inhibiting the degradation of active incretins. Sitagliptin is the first dipeptidyl peptidase-4 inhibitor that increases active incretin concentrations, thereby enhancing their glucoregulatory effects. ${ }^{22-24}$ Many clinical trials have shown that sitagliptin reduces glycated hemoglobin $\left(\mathrm{HbA}_{1 \mathrm{c}}\right)$ concentrations. ${ }^{25,26}$ However, the effects of sitagliptin on sP-selectin, adiponectin, and sRAGE in patients with T2DM are poorly understood. To determine whether sitagliptin has anti-atherosclerotic effects, we assessed its effects on sP-selectin, adiponectin, and sRAGE concentrations in patients with T2DM.

\section{Materials and methods}

\section{Patients}

The study cohort included 72 nondiabetic and 113 diabetic patients (Table 1), selected from among those admitted to
Table I Demographic and clinical characteristics of the diabetic patients and nondiabetic controls

\begin{tabular}{|c|c|c|c|}
\hline & Nondiabetes & Diabetes & $P$-value \\
\hline$n$ & 72 & 113 & \\
\hline Men/women (n) & $39 / 33$ & $60 / 53$ & \\
\hline Age (years) & $62 \pm 6$ & $63 \pm 8$ & NS \\
\hline BMI $\left(\mathrm{kg} / \mathrm{m}^{2}\right)$ & $26.1 \pm 3.9$ & $27.9 \pm 4.6$ & NS \\
\hline FBG (mg/dL) & $102 \pm 21$ & $239 \pm 57$ & $<0.001$ \\
\hline $\mathrm{HbA}_{\mathrm{Ic}}(\%)$ & $5.1 \pm 0.9$ & $7.6 \pm 1.5$ & $<0.01$ \\
\hline $\mathrm{TC}(\mathrm{mg} / \mathrm{dL})$ & $220 \pm 28$ & $236 \pm 37$ & NS \\
\hline HDL-C (mg/dL) & $47 \pm 12$ & $44 \pm 13$ & NS \\
\hline LDL-C (mg/dL) & $133 \pm 32$ & $|4| \pm 42$ & NS \\
\hline \multicolumn{4}{|l|}{ Complications, n (\%) } \\
\hline Angina pectoris & $9(12.5)$ & $16(14.2)$ & NS \\
\hline Heart failure & $5(6.9)$ & $7(6.2)$ & NS \\
\hline Cerebral infarction & $4(5.6)$ & $10(8.8)$ & NS \\
\hline \multicolumn{4}{|l|}{ Medication, n (\%) } \\
\hline Statins & $21(29.2)$ & $27(23.9)$ & NS \\
\hline ARBs & $30(4 I .7)$ & $39(34.5)$ & NS \\
\hline $\mathrm{Ca}$ antagonists & $21(29.2)$ & $26(23.0)$ & NS \\
\hline Aspirin & $7(9.7)$ & $13(11.5)$ & NS \\
\hline
\end{tabular}

Notes: Data are shown as mean \pm SD. $P$-value, diabetic patients versus nondiabetic controls.

Abbreviations: BMI, body mass index; FBG, fasting blood glucose; $\mathrm{HbA}_{1 \mathrm{c}}$, hemoglobin $A_{I c}$; TC, total cholesterol; HDL-C, high-density lipoprotein cholesterol; LDL-C, low-density lipoprotein cholesterol; ARBs, angiotensin II receptor blockers; NS, not significant; SD, standard deviation.

our hospital between April 2011 and March 2014 for the treatment of hypertension, hyperlipidemia, and diabetes. The study protocol was approved by the Institutional Review Board of Kansai Medical University, and written informed consent was obtained from each patient. Individuals were excluded if they had a history (within 3 months prior to enrollment) of inflammatory, coronary artery, or cerebrovascular disease; or if they had clinically detectable hepatic dysfunction (elevated transaminases), infection (fever or an elevated white blood cell count), or malignancy (detected on ultrasound or computed tomography). Of the included patients, 20 were taking aspirin because of a previous cerebral infarction or angina pectoris, 69 were taking angiotensin II receptor blockers, 47 were taking $\mathrm{Ca}$ antagonists, and 48 were taking statins (Table 1). The doses of these drugs were not adjusted, and there were no other changes to drug therapy, during the present study.

\section{Study design}

Patients were eligible for sitagliptin monotherapy if their diet/exercise therapy had continued unchanged for 3 months. Patients who had used a biguanide (metformin), a sulfonylurea (glibenclamide or glimepiride), a thiazolidinedione (glitazone), or insulin for 3 months were eligible for combination therapy with that agent plus sitagliptin. Patients with almost normal renal function (serum creatinine 
[S-CRTN] $<2.0 \mathrm{mg} / \mathrm{dL}$ ) were administered sitagliptin (50 mg/day) once daily for 6 months. Clinical and biochemical data were obtained before and 3 and 6 months after starting sitagliptin treatment.

\section{Measurement of soluble molecules and adiponectin}

Blood samples from patients and controls under fasting conditions were collected into tubes with or without sodium citrate and allowed to clot at room temperature for a minimum of 1 hour. Citrated plasma or serum was isolated by centrifugation at $1,000 \times \mathrm{g}$ for $20 \mathrm{~min}$ utes at $4{ }^{\circ} \mathrm{C}$ and stored at $-30^{\circ} \mathrm{C}$ until analyzed. Plasma concentrations of sP-selectin, sE-selectin, sVCAM-1, and monocyte chemoattractant protein-1 (MCP-1) were measured using monoclonal antibody-based ELISA kits (Invitrogen Inc., Camarillo, CA, USA), plasma adiponectin was measured with adiponectin ELISA kits (Otsuka Pharmaceutical Co., Ltd. Tokyo, Japan), and serum sRAGE was measured using sRAGE ELISA kits (Quantikine; R\&D Systems, Minneapolis, MN, USA). The recombinant products and standard solutions provided with each kit were used as positive controls in each assay, and all the procedures were performed according to the manufacturers' instructions.

Diabetic patients were divided into two subgroups based on their adiponectin responses to sitagliptin treatment. Responders were defined as patients showing a $\geq 1.5$-fold increase in plasma adiponectin levels, relative to baseline, after sitagliptin treatment, whereas nonresponders were defined as those with a $<1.5$-fold increase in plasma adiponectin.

\section{Statistics}

Data were expressed as mean \pm standard deviation and were analyzed using multivariate regression analysis, as appropriate. Between-group comparisons were analyzed using the Newman-Keuls test and Scheffe's test. The correlation between uric acid concentration and continuous variables was assessed using multivariate linear regression analysis. The significance of differences among variables was determined by analysis of variance (ANOVA). $P$-values less than 0.05 were considered statistically significant. All the analyses were performed using the Stat Flex program (V 6.0).

\section{Results}

Patient demographic and clinical characteristics were similar in the diabetic and nondiabetic groups, except for fasting blood glucose and $\mathrm{HbA}_{1 \mathrm{c}}$ concentrations (Table 1).
The levels of blood urea nitrogen, S-CRTN, C-reactive protein, MCP-1, sP-selectin, sE-selectin, and sVCAM-1 were higher in diabetic than in nondiabetic patients (Table 2). However, adiponectin was lower in diabetic than in nondiabetic patients (Table 2).

Using univariate and multivariate regression analyses, we investigated the associations between 16 variables and $\mathrm{HbA}_{1 \mathrm{c}}$ concentration in diabetic patients (Table 3 ). Univariate analysis showed that body mass index, angina pectoris, low-density lipoprotein cholesterol, sP-selectin, sE-selectin, sVCAM-1, MCP-1, sRAGE, and adiponectin were factors significantly associated with $\mathrm{HbA}_{1 \mathrm{c}}$, whereas sP-selectin, sVCAM-1, MCP-1, and adiponectin were significantly correlated with $\mathrm{HbA}_{1 \mathrm{c}}$ in multivariate analysis.

Renal function was almost normal (S-CRTN $<2.0$ $\mathrm{mg} / \mathrm{dL})$ in 65 of the 113 diabetic patients. Administration of sitagliptin to these 65 patients for 3 months significantly reduced fasting blood glucose and $\mathrm{HbA}_{1 \mathrm{c}}$ (data not shown), and administration for 6 months significantly reduced plasma concentrations of $\mathrm{sP}$-selectin, $\mathrm{sE}$-selectin, sVCAM-1, and MCP-1 relative to baseline $(P<0.05$ each; Figure 1A-D). Sitagliptin treatment significantly increased adiponectin concentrations after $3(P<0.05)$ and $6(P<0.01)$ months relative to baseline (Figure $1 \mathrm{~F})$. Sitagliptin also increased sRAGE concentration relative to baseline, although the differences were not statistically significant (Figure 1E).

Table 2 Plasma levels of soluble factors, chemokines, and adiponectin in the nondiabetic controls and diabetic patients

\begin{tabular}{llll}
\hline & Nondiabetes & Diabetes & P-value \\
\hline $\mathrm{n}$ & 72 & $1 \mathrm{I} 3$ & \\
BUN $(\mathrm{mg} / \mathrm{dL})$ & $18.9 \pm 8.8$ & $26.6 \pm 14.9$ & $<0.05$ \\
S-CRTN $(\mathrm{mg} / \mathrm{dL})$ & $0.62 \pm 0.19$ & $1.95 \pm 1.07$ & $<0.05$ \\
AST $(\mathrm{mg} / \mathrm{dL})$ & $30 \pm 12$ & $34 \pm 15$ & $\mathrm{NS}$ \\
ALT $(\mathrm{mg} / \mathrm{dL})$ & $28 \pm \mathrm{I} 4$ & $32 \pm 19$ & $\mathrm{NS}$ \\
T-BIL $(\mathrm{mg} / \mathrm{dL})$ & $0.71 \pm 0.34$ & $0.87 \pm 0.5 \mathrm{I}$ & $\mathrm{NS}$ \\
LD $(\mathrm{U} / \mathrm{L})$ & $218 \pm 66$ & $232 \pm 82$ & $\mathrm{NS}$ \\
CRP $(\mathrm{mg} / \mathrm{dL})$ & $0.82 \pm 0.79$ & $1.24 \pm 0.85$ & $<0.05$ \\
MCP-I $(\mathrm{pg} / \mathrm{mL})$ & $344 \pm 82$ & $566 \pm 129$ & $<0.0 \mathrm{I}$ \\
sP-selectin $(\mathrm{ng} / \mathrm{mL})$ & $232 \pm 73$ & $278 \pm 104$ & $<0.05$ \\
sE-selectin $(\mathrm{ng} / \mathrm{mL})$ & $72 \pm 39$ & $95 \pm 48$ & $<0.05$ \\
sVCAM-I $(\mathrm{ng} / \mathrm{mL})$ & $632 \pm 139$ & $924 \pm 148$ & $<0.0 \mathrm{I}$ \\
sRAGE $(\mathrm{pg} / \mathrm{mL})$ & $\mathrm{I}, 030 \pm 478$ & $\mathrm{I}, 220 \pm 670$ & $\mathrm{NS}$ \\
Adiponectin $(\mu \mathrm{gg} / \mathrm{mL})$ & $4.54 \pm \mathrm{I} .0 \mathrm{I}$ & $2.52 \pm 1.43$ & $<0.0 \mathrm{I}$ \\
\hline
\end{tabular}

Notes: Data are shown as mean \pm SD. $P$-value, diabetic patients versus nondiabetic controls.

Abbreviations: BUN, blood urea nitrogen; S-CRTN, serum creatinine; AST, aspartate aminotransferase; ALT, alanine transaminase; T-BIL, total bilirubin; LD, lactate dehydrogenase; CRP, C-reactive protein; MCP-I, monocyte chemoattractant protein-I; sP-selectin, soluble P-selectin; sE-selectin, soluble E-selectin; sVCAM-I, soluble vascular cell adhesion molecule-I; sRAGE, soluble receptor for advanced glycation end product; NS, not significant; SD, standard deviation. 
Table 3 Multiregression analysis on $\mathrm{HbA}_{\mathrm{Ic}}$ in diabetic patients

\begin{tabular}{|c|c|c|c|c|}
\hline \multirow[t]{2}{*}{ Analysis } & \multicolumn{2}{|c|}{ Univariate } & \multicolumn{2}{|c|}{ Multivariate } \\
\hline & $\beta$ & $P$-value & $\beta$ & $P$-value \\
\hline Age (years) & 0.2155 & 0.08793 & & \\
\hline Sex (men) & -0.0775 & 0.36417 & & \\
\hline BMI $\left(\mathrm{kg} / \mathrm{m}^{2}\right)$ & 0.3847 & $0.00917^{*}$ & 0.2755 & 0.73116 \\
\hline Angina pectoris (\%) & 0.3277 & $0.04726 *$ & 0.2311 & 0.10339 \\
\hline Heart failure (\%) & 0.1753 & 0.26354 & & \\
\hline Cerebral infarction (\%) & 0.2346 & 0.06617 & & \\
\hline $\mathrm{TC}(\mathrm{mg} / \mathrm{dL})$ & -0.0896 & 0.25331 & & \\
\hline HDL-C (mg/dL) & -0.1279 & 0.36972 & & \\
\hline LDL-C (mg/dL) & 0.4533 & $0.00172 *$ & 0.3159 & 0.05379 \\
\hline $\mathrm{CRP}(\mathrm{mg} / \mathrm{dL})$ & 0.2374 & 0.07223 & & \\
\hline sP-selectin $(\mathrm{ng} / \mathrm{mL})$ & 0.4377 & $0.00188^{*}$ & 0.3284 & $0.04549 *$ \\
\hline $\mathrm{sE}$-selectin $(\mathrm{ng} / \mathrm{mL})$ & 0.3982 & $0.00774 *$ & 0.2863 & 0.06127 \\
\hline sVCAM-I (ng/mL) & 0.4328 & $0.00196 *$ & 0.3218 & $0.04673 *$ \\
\hline MCP-I (pg/mL) & 0.5985 & $0.00017^{*}$ & 0.4233 & $0.01163 *$ \\
\hline sRAGE (pg/mL) & -0.3699 & $0.01029 *$ & -0.2611 & 0.07356 \\
\hline Adiponectin $(\mu \mathrm{g} / \mathrm{mL})$ & -0.6172 & $<0.0000 I^{*}$ & -0.5672 & $0.00234 *$ \\
\hline
\end{tabular}

Note: $\beta$ indicates standardized regression coefficients. *indicates statical significance $(P<0.05)$

Abbreviations: $\mathrm{HbA}_{1 \mathrm{c}}$, hemoglobin $\mathrm{A}_{\mathrm{Ic}}$; $\mathrm{BMI}$, body mass index; $\mathrm{TC}$, total cholesterol; HDL-C, high-density lipoprotein cholesterol; LDL-C,low-density lipoprotein cholesterol; $\mathrm{CRP}$, C-reactive protein; sP-selectin, soluble P-selectin; sE-selectin, soluble E-selectin; sVCAM-I, soluble vascular cell adhesion molecule-I;MCP-I, monocyte chemoattractant protein-I; sRAGE, soluble receptor for advanced glycation end product.

We divided diabetic patients into two subgroups according to their adiponectin response to sitagliptin treatment. Responders showed significant reductions in plasma concentrations of sP-selectin, sE-selectin, sVCAM-1, and MCP-1 relative to baseline $(P<0.01$ for each; Figure $2 \mathrm{~A}-\mathrm{D})$, and all the four concentrations were significantly lower in responders than in nonresponders after 6 months of sitagliptin treatment (two-factor ANOVA; $P<0.05$ each). However, responders showed a significant increase in plasma concentration of sRAGE and adiponectin (Figure 2E and F).

\section{Discussion}

Postprandial hyperglycemia is an early manifestation of T2DM and is caused by the loss of early-phase insulin response. ${ }^{27}$ Chronic hyperglycemia is also associated with accumulation of AGEs. ${ }^{28}$ Diabetic complications may be due to inflammatory and oxidative stresses to endothelial cells caused by AGEs, mainly through RAGE. Circulating concentrations of both cleaved-type sRAGE and endogenous secretory RAGE (esRAGE) are increased in diabetic patients. ${ }^{29-31}$ sRAGE concentrations are linked to reactions between AGE and RAGE, and are affected by various clinical features in T2DM. ${ }^{31-33}$ Interestingly, esRAGE concentration was reported to be negatively correlated with the development of atherosclerosis in patients with $\mathrm{T} 2 \mathrm{DM},{ }^{34}$ with esRAGE increasing after statin treatment. ${ }^{35}$ This study showed that sitagliptin treatment tended to increase sRAGE, although the increase was not statistically significant. However, adiponectin responders showed a significant increase in sRAGE following sitagliptin treatment, in agreement with previous findings. ${ }^{35}$ In addition, sitagliptin treatment also reduced the concentrations of the endothelial cell activation markers
A

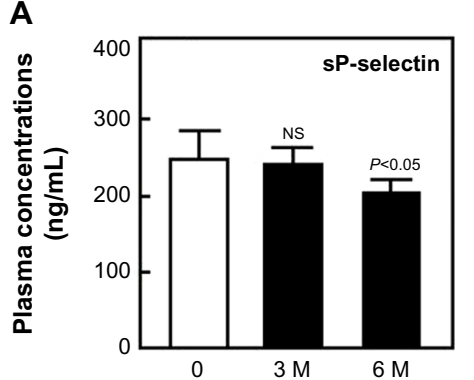

D

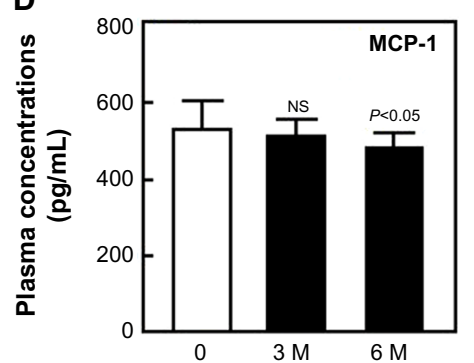

B

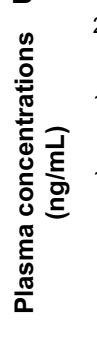

E

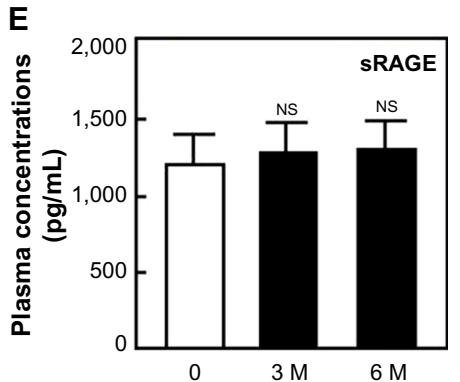

C

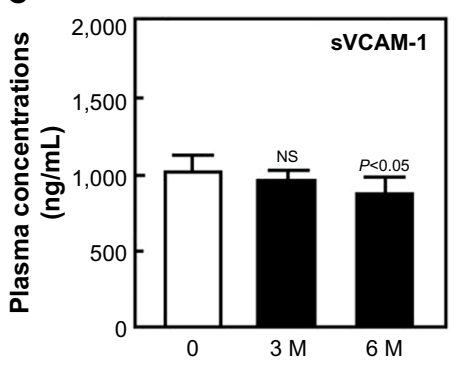

$F$

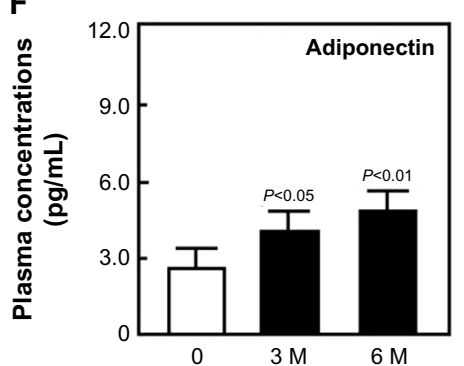

Figure I Plasma concentrations of sP-selectin (A), sE-selectin (B), sVCAM-I (C), MCP-I (D), sRAGE (E), and adiponectin (F) before and after sitagliptin treatment in diabetic patients.

Notes: Data are shown as mean \pm SD. P-value, 0 versus 3 or 6 months (M).

Abbreviations: sP-selectin, soluble P-selectin; sE-selectin, soluble E-selectin; sVCAM-I, soluble vascular cell adhesion molecule-I; MCP-I, monocyte chemoattractant protein-I; sRAGE, soluble receptor for advanced glycation end product; NS, not significant; SD, standard deviation. 

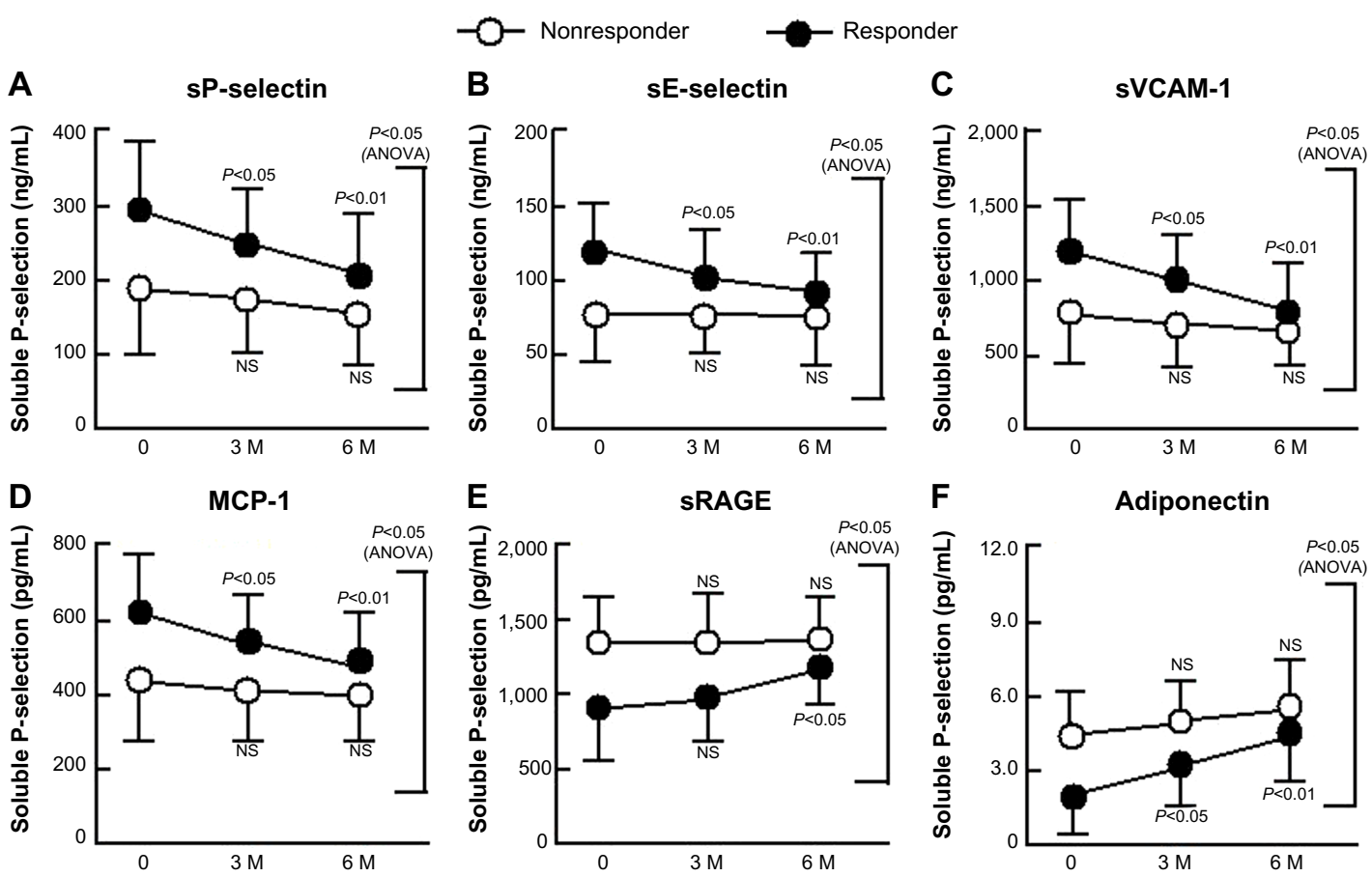

Figure 2 Changes in sP-selectin (A), sE-selectin (B), sVCAM-I (C), MCP-I (D), sRAGE (E), and adiponectin (F) in response to treatment with sitagliptin of patients with type 2 diabetes with and without significant improvements in adiponectin.

Notes: Responder: with a significant improvement of adiponectin. Nonresponder: without a significant improvement of adiponectin. Bars show the mean \pm SD. 0 , before 3 and 6 months $(M)$ after. P-values are for comparison with each baseline parameter ( 0 vs 3 and $6 \mathrm{M}$ ). ANOVA: nonresponder versus responder.

Abbreviations: sP-selectin, soluble P-selectin; ANOVA, analysis of variance; NS, not significant; sE-selectin, soluble E-selectin; sVCAM-I, soluble vascular cell adhesion molecule-I; MCP-I, monocyte chemoattractant protein-I; sRAGE, soluble receptor for advanced glycation end product; SD, standard deviation.

sE-selectin and sVCAM-1 in patients with diabetes, suggesting that sitagliptin has an effect on atherosclerosis related to sRAGE and endothelial cell activation. Further investigations are needed, because our assay of sRAGE could not measure esRAGE specifically.

Postprandial hyperglycemia in diabetic patients may be associated with the activation of endothelial cells. Postprandial hyperglycemia induces oxidative stress via various biochemical pathways, generating superoxide, which reacts with NO to form peroxynitrite. ${ }^{36}$ The resulting decreases in NO concentrations and activity may accelerate vascular inflammation by enhancing the expression of various cytokines and growth factors. ${ }^{37}$ Treatment with sitagliptin was shown to significantly reduce body mass index and waist circumference, ${ }^{38,39}$ as well as to prevent nephropathic complications in patients with T2DM. ${ }^{40}$ Thus, our results suggest that sitagliptin causes the improvement of endothelial dysfunction and atherosclerosis.

Plasma concentrations of adiponectin are lower in obese than in nonobese individuals ${ }^{9}$ and are closely related to wholebody insulin sensitivity. ${ }^{11}$ Plasma adiponectin concentrations are also reduced in patients with T2DM. ${ }^{11}$ Adiponectin has been reported to suppress the attachment of monocytes to endothelial cells ${ }^{37}$ and to play a role in protection against vas- cular injury, suggesting that hypoadiponectinemia is associated with endothelial dysfunction. ${ }^{41}$ Hypoadiponectinemia has also been associated with platelet activation. The level of NO, which regulates platelet activation, is reduced by hypoadiponectinemia, because adiponectin stimulates NO production by vascular endothelial cells..$^{13,14,42}$ Thus, platelet activation due to low NO concentrations occurs in individuals with hypoadiponectinemia. Therefore, the sitagliptin-induced increase in adiponectin may have an antiplatelet effect by enhancing NO production, ${ }^{43}$ as shown by the significant reduction in $\mathrm{sP}$-selectin in diabetic patients treated with sitagliptin.

Various posttranslational modifications, including the glycosylation of lysine residues, have been shown to be necessary for the multimerization of adiponectin. ${ }^{44}$ These intracellular posttranslational processes may be affected by hyperglycemia, leading to functional impairment at the organ level in diabetic patients. ${ }^{45-47}$ Therefore, the sitagliptininduced improvement in postprandial hyperglycemia may alter the posttranslational modification of adiponectin.

This study also found that sitagliptin reduced sP-selectin, sEselectin, sVCAM-1, and MCP-1 concentrations. Grouping of the diabetic patients into two subgroups according to the adiponectin response to sitagliptin treatment showed that the plasma levels of these four markers were significantly reduced in adiponectin 
responders, suggesting that sitagliptin induces adiponectindependent improvements in the plasma levels of sP-selectin, sE-selectin, sVCAM-1, and MCP-1 in diabetic patients.

The exact mechanism by which sitagliptin treatment increases circulating adiponectin concentrations remains unclear, although the gut-derived incretin hormone GLP-1 is likely involved. GLP-1-based therapies have been shown to reduce glucose concentrations and have antiobesity effects in patients with T2DM. ${ }^{48}$ Sitagliptin was found to enhance the secretion of active GLP-1, suggesting that the antidiabetic properties of sitagliptin depend, in part, on GLP- $1 .{ }^{49}$ In addition, GLP-1 was shown to promote adiponectin secretion. ${ }^{50,51}$ Our findings suggest that the effects of sitagliptin on sP-selectin, sE-selectin, sVCAM-1, and MCP-1 concentrations depend on adiponectin. Therefore, sitagliptin may inhibit the progression of atherothrombosis by promoting adiponectin-dependent reductions in plasma $\mathrm{SP}$-selectin, sE-selectin, sVCAM-1, and MCP-1. However, further studies are necessary to elucidate the effects of sitagliptin itself on adiponectin production.

This study had two potential strengths. First, despite the treatment of many T2DM patients with sitagliptin, no previous study had assessed the effects of sitagliptin on serum markers of the disease. Second, it showed that investigation of appropriate serum markers can be used to address atherosclerosis. However, this study also had several limitations. First, changes in clinical parameters such as body mass index were not routinely recorded. Second, we could not identify causative differences in groups of adiponectin responders and nonresponders. Responders had poorer serum values at the onset of sitagliptin treatment, suggesting a genetic/environmental factor associated with these differences. Third, we could not clarify the significance of sRAGE relative to atherosclerosis after sitagliptin treatment. Confirmation of these findings in larger and more particular studies would be useful.

In conclusion, sitagliptin increased circulating sRAGE and adiponectin concentrations in patients with T2DM. In addition, sitagliptin treatment reduced sP-selectin, sEselectin, sVCAM-1, and MCP-1 levels. Sitagliptin may be beneficial in the primary prevention of atherothrombosis in patients with T2DM. ${ }^{52}$ However, large clinical trials are required to test this hypothesis.

\section{Acknowledgments}

This study was partly supported by a grant from the Japan Foundation of Neuropsychiatry and Hematology Research, a Research Grant for Advanced Medical Care from the Ministry of Health and Welfare of Japan, and a Grant (13670760 to SN) from the Ministry of Education, Science and Culture of Japan.

\section{Disclosure}

The authors report no conflicts of interest in this work.

\section{References}

1. Schafer AI. The hypercoagulable states. Ann Intern Med. 1985;102(6): 814-828.

2. Frade LJG, de la Calle H, Alava I, Navarro JL, Creighton LJ, Gaffiney PJ. Diabetes as a hypercoagulable state: its relationship with fibrin fragments and vascular damage. Thromb Res. 1987;47(5):533-540.

3. Seshasal SR, Kaptoge S, Thompson A, et al. Diabetes mellitus, fasting glucose, and risk of cause-specific death. $N$ Engl J Med. 2011;364(9): 829-841.

4. Scheen AJ. Cardiovascular effects of gliptins. Nat Rev Cardiol. 2013; 10(2):73-84.

5. Cominacini L, Pasini AF, Garbin U, et al. Elevated levels of soluble E-selectin in patients with IDDM and NIDDM: relation to metabolic control. Diabetologia. 1995;38(9):1122-1124.

6. Lim YC, Snapp K, Kansas GS, Camphausen R, Ding H, Luscinskas FW. Important contributions of P-selectin glycoprotein ligand-1-mediated secondary capture to human monocyte adhesion to P-selectin, E-selectin, and TNF- $\alpha$-activated endothelium under flow in vitro. J Immunol. 1998;161(5):2501-2508.

7. Nomura S, Shouzu A, Omoto S, Nishikawa M, Fukuhara S. Significance of chemokines and activated platelets in patients with diabetes. Clin Exp Immunol. 2000;121(3):437-443.

8. Nakagami T. Hyperglycaemia and mortality from all cause and from cardiovascular disease in five populations of Asian origin. Diabetologia. 2004;47(3):385-394.

9. Ouchi N, Kihara S, Arita Y, et al. Adiponectin, an adipocyte-derived plasma protein, inhibits endothelial NF-kappa B signaling through a cAMP-dependent pathway. Circulation. 2000;102(11):1296-1301.

10. Arita Y, Kihara S, Ouchi N, et al. Paradoxical decrease of an adiposespecific protein, adiponectin, in obesity. Biochem Biophys Res Com. 1999;257(1):79-83.

11. Hotta K, Funahashi T, Arita Y, et al. Plasma concentrations of a novel, adipose-specific protein, adiponectin, in type 2 diabetes patients. Arterioscler Thromb Vasc Biol. 2000;20(6):1595-1599.

12. Weyer C, Funahashi T, Tanaka S, et al. Hypoadiponectinemia in obesity and type 2 diabetes: close association with insulin resistance and hyperinsulinemia. J Clin Endocrinol Metab. 2001;86(5):1930-1935.

13. Chen H, Montagnani M, Funahashi T, Shimomura I, Quon MJ. Adiponectin stimulates production of nitric oxide in vascular endothelial cells. J Biol Chem. 2003;278(45):45021-45026.

14. Hattori Y, Suzuki M, Hattori S, Kasai K. Globular adiponectin upregulates nitric oxide production in vascular endothelial cells. Diabetologia. 2003;46(11):1543-1549.

15. Zieman SJ, Melenovsky V, Clattenburg L, et al. Advanced glycation end product crosslink breaker (alagebrium) improves endothelial function in patients with isolated systolic hypertension. $J$ Hypertens. 2007;25(3): 577-583.

16. Hofmann MA, Drury S, Fu C, et al. RAGE mediates a novel proinflammatory axis: a central cell surface receptor for S100/calgranulin polypeptides. Cell. 1999;97(7):889-901.

17. Haslbeck KM, Schleicher E, Bierhaus A, et al. The AGE/RAGE/ NF-kB pathway may contribute to the pathogenesis of polyneuropathy in impaired glucose tolerance (IGT). Exp Clin Endocrinol Diabetes. 2005;113(5):288-291.

18. Bierhaus A, Nawroth PP. Multiple levels of regulation determine the role of the receptor for AGE (RAGE) as common soil in Kalousova M inflammation, immune responses and diabetes mellitus and its complications. Diabetologia. 2009;52(11):2251-2263.

19. Yan SF, Yan SD, Ramasamy R, Schmidt AM. Tempering the wrath of RAGE: an emerging therapeutic strategy against diabetic complications, neurodegeneration, and inflammation. Ann Med. 2009;41(6): 408-422. 
20. Kalousová M, Jáchymová M, Mestek O, et al. Receptor for advanced glycation end products-soluble form and gene polymorphisms in chronic haemodialysis patients. Nephrol Dial Transplant. 2007;22(7): 2020-2026.

21. Grossin N, Wautier MP, Meas T, Guillausseau PJ, Massin P, Wautier JL. Severity of diabetic microvascular complications is associated with a low soluble RAGE level. Diabetes Metab. 2008;34(4):392-395.

22. Herman GA, Stevens C, Van Dyck K, et al. Pharmacokinetics and pharmacodynamics of sitagliptin, an inhibitor of dipeptidyl peptidase IV, in healthy subjects: results from two randomized, double-blind, placebo-controlled studies with single oral doses. Clin Pharmacol Ther. 2005;78(6):675-688.

23. Herman GA, Bergman A, Stevens C, et al. Effect of single oral doses of sitagliptin, a dipeptidyl peptidase-4 inhibitor, on incretin and plasma glucose levels after an oral glucose tolerance test in patients with type 2 diabetes. J Clin Endocrinol Metab. 2006;91(11):4612-4619.

24. Heransen K, Kipnes M, Luo E, et al. Efficacy and safety of the dipeptidyl peptidase- 4 inhibitor, sitagliptin, in patients with type 2 diabetes mellitus inadequately controlled on glimepiride alone or on glimepiride and metformin. Diabetes Obes Metab. 2007;9(5):733-745.

25. Iwamoto Y, Taniguchi T, Nonaka K, et al. Dose-ranging efficacy of sitagliptin, a dipeptidyl peptidase-4 inhibitor, in Japanese patients with type 2 diabetes mellitus. Endocr J. 2010;57(5):383-394.

26. Kim SA, Shim WH, Lee EH, et al. Predictive clinical parameters for the therapeutic efficacy of sitagliptin in Korean type 2 diabetes mellitus. Diabetes Metab J. 2011;35(3):159-165.

27. Polonsky KS, Given BD, Hirsch LJ, et al. Abnormal patterns of insulin secretion in non-insulin-dependent diabetes mellitus. $N$ Engl J Med 1988;318(19):1231-1239.

28. Wendt T, Tanji N, Guo J, et al. Glucose, glycation, and RAGE: implications for amplification of cellular dysfunction in diabetic nephropathy. J Am Soc Nephrol. 2003;14(5):1383-1395.

29. Soro-Paavonen A, Watson AM, Li J, et al. Receptor for advanced glycation end products (RAGE) deficiency attenuates the development of atherosclerosis in diabetes. Diabetes. 2008;57(9):2461-2469.

30. Thomas MC, Söderlund J, Lehto M, et al. Soluble receptor for AGE (RAGE) is a novel independent predictor of all-cause and cardiovascular mortality in type 1 diabetes. Diabetologia. 2011;54(10):2669-2677.

31. Koyama H, Shoji T, Yokoyama H, et al. Plasma level of endogenous secretory RAGE is associated with components of the metabolic syndrome and atherosclerosis. Arterioscler Thromb Vasc Biol. 2005;25(12): 2587-2593.

32. Gohda T, Tanimoto M, Moon JY, et al. Increased serum endogenous secretory receptor for advanced glycation end-product (esRAGE) levels in type 2 diabetic patients with decreased renal function. Diabetes Res Clin Pract. 2008;81(2):196-201.

33. Semba RD, Ferrucci L, Fink JC, et al. Advanced glycation end products and their circulating receptors and level of kidney function in older community-dwelling women. Am J Kidney Dis. 2009;53(1):51-58.

34. Katakami N, Matsuhisa M, Kaneto H, Yamasaki Y. Serum endogenous secretory RAGE levels are inversely associated with carotid IMT in type 2 diabetic patients. Atherosclerosis. 2007;190(1):22-23.

35. Tam HL, Shiu SW, Wong Y, Chow WS, Betteridge DJ, Tan KC. Effects of atorvastatin on serum soluble receptors for advanced glycation end-products in type 2 diabetes. Atherosclerosis. 2010;209(1): 173-177.
36. Kurowska EM. Nitric oxide therapies in vascular diseases. Curr Pharm Des. 2002;8(3):155-166.

37. Ouchi N, Kihara S, Arita Y, et al. Novel modulator for endothelial adhesion molecules: adipocyte-derived plasma protein, adiponectin. Circulation. 1999;100(25):2473-2476.

38. Maeda H, Kubota A, Tanaka Y, Takeuchi Y, Matsuba I. The safety, efficacy and predictors for $\mathrm{HbA}_{1 \mathrm{c}}$ reduction of sitagliptin in the treatment of Japanese type 2 diabetes. Diabetes Res Clin Pract. 2012;95(1): e20-e22.

39. Hong ES, Khang AR, Yoon JW, et al. Comparison between sitagliptin as add-on therapy to insulin and insulin dose-increase therapy in uncontrolled Korean type 2 diabetes: CSI study. Diabetes Obes Metab. 2012;14(9):795-802.

40. Mori H, Okada Y, Arao T, Tanaka Y. Sitagliptin improves albuminuria in patients with type 2 diabetes mellitus. J Diabetes Invest. 2014;5(3) 313-319.

41. Shimabukuro M, Higa N, Asahi T, et al. Hypoadiponectinemia is closely linked to endothelial dysfunction in man. J Clin Endocr Metab. 2003;88(7):3236-3240.

42. Nomura S, Shouzu A, Omoto S, et al. Correlation between adiponectin and reduction of cell adhesion molecules after pitavastatin treatment in hyperlipidemic patients with type 2 diabetes mellitus. Thromb Res. 2008;122(1):39-45.

43. Gupta AK, Verma AK, Kailashiya J, et al. Sitagliptin: antiplatelet effect in diabetes and healthy volunteers. Platelets. 2012;23(8):565-570.

44. Wang Y, Lam KS, Chan L, et al. Post-translational modifications of the four conserved lysine residues within the collagenous domain of adiponectin are required for the formation of its high molecular weight oligomeric complex. J Biol Chem. 2006;281(24):16391-16400.

45. Fülöp N, Marchase RB, Chatham JC. Role of protein O-linked $\mathrm{N}$-acetyl-glucosamine in mediating cell function and survival in the cardiovascular system. Cardiovasc Res. 2007;73(2):288-297.

46. Fülöp N, Mason MM, Dutta K, et al. Impact of type 2 diabetes and aging on cardiomyocyte function and O-linked N-acetylglucosamine levels in the heart. Am J Physiol Cell Physiol. 2007;292(4):C1370-C1378.

47. Ochiai H, Ooka H, Shida C, Ishikawa T, Inoue D, Okazaki R. Acarbose treatment increases serum total adiponectin levels in patients with type 2 diabetes. Endocr J. 2008;55(3):549-556.

48. Knop FK, Vilsbøll T, Larsen S, Madsbad S, Holst JJ, Krarup T. No hypoglycemia after subcutaneous administration of glucagons-like peptide-1 in lean type 2 diabetic patients and in patients with diabetes secondary to chronic pancreatitis. Diabetes Care. 2003;26(9):2581-2587.

49. Ishibashi Y, Matsui T, Takeuchi M, Yamagishi S. Sitagliptin augments protective effects of GLP-1 against advanced glycation end product receptor axis in endothelial cells. Horm Metab Res. 2011;43(1): 731-734.

50. Pocai A, Carrington PE, Adams JR, et al. Glucagon-like peptide 1/ glucagons receptor dual agonism reverses obesity in mice. Diabetes. 2009;58(10):2258-2266.

51. Kim Chung le T, Hosaka T, Yoshida M, et al. Exendin-4, a GLP-1 receptor agonist, directly induces adiponectin expression through protein kinase A pathway and prevents inflammatory adipokine expression. Biochem Biophys Res Comm. 2009;390(3):613-618.

52. Dhindsa S, Jialal I. Potential anti-atherosclerotic effects of dipeptidyl peptidase- 4 inhibitors in type 2 diabetes mellitus. Curr Diabetes Rep. 2014;14(2):463.

Diabetes, Metabolic Syndrome and Obesity: Targets and Therapy

\section{Publish your work in this journal}

Diabetes, Metabolic Syndrome and Obesity: Targets and Therapy is an international, peer-reviewed open-access journal committed to the rapid publication of the latest laboratory and clinical findings in the fields of diabetes, metabolic syndrome and obesity research Original research, review, case reports, hypothesis formation, expert

\section{Dovepress}

opinion and commentaries are all considered for publication. The manuscript management system is completely online and includes a very quick and fair peer-review system, which is all easy to use. Visit http://www.dovepress.com/testimonials.php to read real quotes from published authors. 